\title{
MANIFESTAÇÕES DE ALUNOS INICIANTES DE UM CURSO DE LICENCIATURA EM CIÊNCIAS FRENTE AO PAPEL ORGANIZADOR DA ESCRITA ALGÉBRICA NA RESOLUÇÃO DE PROBLEMAS MATEMÁTICOS
}

\author{
MANIFESTATIONS OF BEGINNERS STUDENTS AT A SCIENCE COURSEFACCING THE \\ ORGANIZING ROLE OF ALGERIC WRITING IN THE SOLUTION OF MATHEMATICAL PROBLEMS
}

\author{
WAGNER MARCELO POMMER*
}

\section{RESUMO}

Esta pesquisa teve como objetivo verificar se e como alunos ingressantes de um curso de Licenciatura em Ciências expressam compreensão do papel do equacionamento frente a problemas matemáticos envolvendo equações diofantinas lineares. Aplicamos dois problemas a alunos ingressantes da licenciatura em Ciências de uma universidade pública em São Paulo em horário extra-aula. Os resultados revelaram que os alunos escreveram a equação que representa o problema, mas não a utilizou explicitamente para a busca de soluções, que se situou no campo aritmético. Porém, houve um tipo de organização operacional que revela indícios de uma compreensão inicial e um uso não-consciente do papel das equações como organizadora da resolução de problemas matemáticos envolvendo equações diofantinas lineares.

Palavras-chave: Equações Diofantinas Lineares. Situação-problema. Licenciatura em Ciências.

\section{ABSTRACT}

This article aimed to verify if and how $1^{\text {st }}$ year students of a Science Teaching Course express understanding of equating role facing to mathematical problems involving Linear Diophantine Equations. We applied two problems to incoming students of a Science Teaching Course in a public university at São Paulo State at an extra class moment. The results revealed that students wrote the equation that represents the problem, but they did not use it explicitly for the search for solutions, which was mainly located in the arithmetic field. However, there was a kind of operating organization that reveals evidences of an initial understanding and non-conscious use concerning the role of equations as an organizer of mathematical problems solving which involves linear diophantine equations.

Keywords: Linear Diophantine equation. Problem. Science teaching courses.

\footnotetext{
* Doutor em Educação. Universidade Federal de São Paulo. E-mail: wagner.pommer@unifesp. br. Orcid: http://orcid.org/0000-0002-6138-1279.
} 


\section{INTRODUÇÃO}

A profissão docente apresenta enormes desafios. Perrenoud (1993) coloca que os professores se deparam com 'contradições impossivveis de serem superadas'. Estas contradições se manifestam nas decisões que o professor deve tomar, tais como:

[...] avançar no programa ou atender às necessidades dos alunos? Forjar hierarquias ou praticar uma avaliação formativa? Desenvolver a autonomia ou o conformismo? [...] Dar ênfase aos saberes, aos métodos e à instrução ou aos valores, à educação e à socialização? Valorizar a competição ou a cooperação? Dar a cada um a impressão de que é competente ou levar os alunos a verem a si mesmos com mais lucidez? Dar preferência à estruturação do pensamento e da expressão ou estimular a criatividade e a comunicação? (PERRENOUD, 1993, p. 9).

Complementando estas considerações, Barlow (1999) discute questões sobre a profissão docente. 0 autor destaca que 0 ensino se configura como uma profissão:

[...] tão paradoxal, que quem a exerce deveria possuir, ao mesmo tempo, as qualidades de estrategista e de tático de um general do exército; as qualidades de planejador e de líder de um dirigente de empresa; a habilidade e a delicadeza de um artesão; a destreza e a imaginação de um artista; a astúcia de um político; o profissionalismo de um clínico-geral; a imparcialidade de um juiz; a engenhosidade de um publicitário; os talentos, a ousadia e os artifícios de um ator; 0 senso de observação de um etnólogo; a erudição de um hermeneuta; 0 charme de um sedutor; a destreza de um mágico e muitas outras qualidades cuja lista seria praticamente ilimitada (p. 145-146).

No que tange as competências dos futuros docentes, relativas à gestão de tarefas para os alunos se situarem diante dos saberes, esta capacidade se situa no âmbito da compreensão do papel a ser desempenhado pelo professor.

Nesse particular, o professor deve ter conhecimento dos vários meios didáticos para trabalhar os conhecimentos. Assim, há necessidade da proposição de situações de aprendizagem, na qual se estimule 0 desenvolvimento da autonomia, da ação e da reflexão por parte dos alunos, diante dos desafios dos conhecimentos propostos pelas atividades encaminhadas pelo professor.

Estas atribuições representam um aspecto intrincado da profissão docente, quais sejam, aquelas relacionadas à formação de seus saberes e a transformação dos conhecimentos dos professores em situações de ensino e aprendizagem. Estes aspectos se constituem como um conjunto a ser desenvolvido na etapa de formação inicial em cursos de licenciatura de Matemática e de Ciências Naturais.

Scheffer e Aimi (2004) pontuam que a licenciatura deve tornar possível a formação em exercício do futuro professor, em um momento educativo de articulação entre a prática pedagógica e a busca de referenciais teóricos e metodológicos que fomentem o pleno exercício do papel de educador.

Ainda, um curso de licenciatura deve ter como princípio "[...] a formação de um professor não apenas dotado de competência em sua área de saber, mas também capaz de compreender a diversidade, de modo a corresponder às expectativas daqueles que hoje frequentam a escola" (SÃO PAUL0, 2004, p. 2).

Ao ingressarem nas Licenciaturas, os alunos usualmente apresentam um rol de expectativas para a consolidação de conhecimentos conceituais. Porém, é importante ressaltar a importância dos 
aspectos procedimentais e atitudinais (Coll, 1996), que tecerão uma das nuances de formação do licenciando para a futura profissão docente.

As licenciaturas, ao se constituírem como espaço essencial para a formação e conciliação dos aspectos teóricos e práticos, devem favorecer momentos e situações diversificadas adequadas à formação do futuro professor. Em especial, atentamos para a necessária capacitação inicial do licenciando em preparar e gestar situações de ensino e aprendizagem.

Para D’Ambrosio (1993), o professor de Matemática deve ter consciência e clareza no que consiste a própria disciplina, o que fundamenta a atividade matemática e quais as condições propícias à aprendizagem matemática em sala de aula.

Em particular, a Álgebra tem sido destacada como um dos entraves ao percurso do estudante da escolaridade básica, conforme destacam Bianchini e Machado (2010). Em particular, nos posicionamos com relação às discussões na Educação Algébrica, área que aponta a necessidade do licenciando ter formação para enfrentar a complexidade do futuro trabalho docente.

Assim, partimos do pressuposto, há tempo muito defendido, que a Álgebra é uma ferramenta essencial para a Matemática e outras áreas do conhecimento. Este fato demanda certa preocupação em como viabilizar essa formação para alunos da Educação Básica, conforme destaca a Base Nacional Comum Curricular, expressa em Brasil (2017).

Duval (2011 apud Brandt; Moretti, 2018) observa que uma das dificuldades dos alunos secundaristas se situa na resolução de problemas no tocante ao ensino da álgebra. Pozo (1988) complementa que a resolução de problemas é uma ferramenta básica e implica na aquisição de diferentes procedimentos e estratégias para dar respostas a situações variáveis e diferentes.

Tendo como foco a formação inicial de professores, o objetivo desta pesquisa foi verificar se e como alunos ingressantes das licenciaturas em Ciências expressam compreensão do papel do equacionamento frente a problemas envolvendo equações diofantinas lineares.

\section{O QUADRO TEÓRICO}

No Brasil, diversos cursos que apresentam relação com o ensino de disciplinas básicas da escolaridade básica ainda mantêm vínculo a um currículo centrado em conteúdos, na modalidade denominada bacharelado. Esta etapa se centra na aquisição de conteúdos conceituais ou factuais, na expressão de Coll (1996), inseridos nas diversas disciplinas do currículo das Instituições de Ensino Superior.

Depois de concluída esta primeira etapa, os alunos podem ou não cursar a licenciatura, oferecida como um complemento pedagógico à formação do futuro docente, formato de currículo conhecido como modelo '3+1', destacado em Gatti (2010).

No final dos anos de 1930, a partir da formação de bacharéis nas poucas universidades então existentes, acrescenta-se um ano com disciplinas da área de educação para a obtenção da licenciatura, esta dirigida à formação de docentes para o 'ensino secundário', formação que veio a denominar-se popularmente' $3+1$ ' (GATTI, 2010, p. 1356, grifo nosso).

Mesmo com ajustes parciais em razão das novas as Diretrizes Curriculares Nacionais para a Formação de Professores conforme Brasil, (2003), nas licenciaturas ainda prevalece 0: 
[...] foco na área disciplinar específica, com pequeno espaço para a formação pedagógica. Adentramos o século XXI em uma condição de formação de professores nas áreas disciplinares em que, mesmo com as orientações mais integradoras quanto à relação "formação disciplinar/formação para a docência", na prática ainda se verifica a prevalência do modelo consagrado no início do século XX para essas licenciaturas (GATTI, 2010, p. 1357).

Neste viés, o currículo apresenta uma distribuição desarticulada e desigual de responsabilidades, pois subentende a formação de professores "[...] como uma superposição de dois conjuntos de conhecimentos, em que 0 aprendizado do saber disciplinar antecede 0 aprendizado do saber pedagógico" (SÃO PAULO, 2004, p. 1).

Ainda, 0 denominado modelo ' $3+1$ ' promove uma visão invertida. As disciplinas conhecidas como 'conteudistas' transparecem aos alunos como aquelas que seriam as necessárias e suficientes ao futuro trabalho do professor, ficando delegado às disciplinas pedagógicas um aspecto de idealismo, distante da difícil e complexa tarefa do exercício do ofício docente.

Estes fatores apontados caracterizam um desvio em relação ao objetivo maior das licenciaturas - a formação de professores - visto que para a promoção do "[...] crescimento do ser humano há de se ter uma intenção educativa diferente da usual nos conteúdos e na forma de sua aplicação" (COLL, 1996, p. 13).

Para compreender o pensamento e comportamento dos indivíduos, Coll (1996) tipifica os conteúdos em conceituais, procedimentais e atitudinais, que correspondem ao que é preciso saber? 0 que é preciso saber fazer? e o que é preciso ser?, itens que deveriam ser observados nos processos de aprendizagem ou de ensino.

Usualmente, as disciplinas que enfatizam os conteúdos têm como foco 0 trabalho com a consolidação dos conhecimentos. Em contrapartida, aquelas ligadas à formação educacional são mais voltadas ao desenvolvimento dos conteúdos procedimentais e atitudinais, relativas ao exercício profissional docente, com aspectos enfatizados na atual Base Nacional Comum Curricular, descrita em Brasil (2017).

Porém, no entorno da necessária preocupação com a formação do professor, desde o ingresso da Universidade, urge refletir e agir sobre um princípio essencial: "[...] os conteúdos ligados à formação específica e os ligados à formação profissional do professor devem enriquecer-se mutuamente" (SÃO PAULO, 2004, p. 5).

Os PCNEM enfatizam a importância de propostas práticas partindo-se da ideia que a aprendizagem em Matemática "[...] deve estar vinculada ao domínio de um saber fazer matemática e de um saber pensar matemático" (BRASIL, 1998, p. 41).

Lüdke (1994), Fiorentini et al. (2002) e Moreira e David (2005) destacam a necessidade de se repensar a formação inicial do licenciando através de práticas de articulação entre conteúdos e aspectos relativos a formação pedagógica, de modo a promover uma boa formação do futuro professor da escolaridade básica.

Um dos modos de impulsionar tais práticas pode ser encontrado em Perrenoud (2002), autor que argumenta ser essencial disponibilizar espaços onde possa ocorrer uma reflexão do professor, buscando conciliar a resolução de problemas, 0 tempo de atuação em campo e 0 tempo de análise do que foi realizado.

Para situar um modo de ser, agir e se constituir como professor, Fiorentini; Souza Jr.; Melo (1998) e Tardif (2002) propõem um trabalho com os saberes experienciais ou da prática, que são aqueles 
advindos das articulações realizadas entre os saberes pedagógicos, disciplinares e curriculares, impulsionadas pelas interações advindas das múltiplas dimensões do exercício da profissão docente.

Os saberes experienciais, construídos pelos professores durante a própria prática profissional, imbricados por momentos de reflexão, são uma espécie de "[...] núcleo vital do saber docente, núcleo a partir do qual os professores tentam transformar suas relações de interioridade com sua própria prática" (TARDIF, 2002, p. 54).

Ponderamos que uma oportunidade de se estimular uma reflexão em torno dos saberes experienciais é possível e necessária desde a formação inicial da vivência universitária. Este princípio, exposto em São Paulo (2004), é um pilar que poderá contrapor os inconvenientes condicionantes da tendência polarizada e pendular, ainda presente no ensino atual, que consiste em se ater aos conteúdos conceituais, deixando de lado o trabalho com os conceitos procedimentais e atitudinais dos futuros professores da escolaridade básica.

Tardif (2002) e Fiorentini (2005) colocam outro fator de desajustes, que se origina a partir das vivências que ocorrem no grande tempo de convívio dos alunos na escolaridade básica. Com relação a isto Fiorentini (2005) adverte que esta:

[...] imersão prática é necessariamente formadora, pois levam os futuros professores a adquirirem crenças, valores, representações e certezas sobre a prática do ofício de professor, bem como sobre ser aluno. [...] É assim que se constitui a tradição pedagógica, a qual, apesar dos avanços das pesquisas em Educação Matemática, tem feito com que as práticas escolares pouco pareçam evoluir (p. 111).

Dentre as modalidades de se compor um repertório mais apropriado para a prática de ensino do futuro professor e superação das dicotomias na formação docente, um possível caminho é 0 trabalho com a resolução de problemas. A seguir, passamos a delinear a metodologia empregada nesta pesquisa.

\section{METODOLOGIA DE PESQUISA}

A abordagem da pesquisa foi qualitativa a fim de compreender e interpretar o modo utilizado pelos alunos iniciantes de um curso de Licenciatura em Ciências para resolver problemas. Para Strauss (2008), a pesquisa qualitativa tem aspecto exploratório, de modo a estimular a exposição de crenças e opiniões dos atores participantes, para que estes pensem livremente a respeito do que estão realizando durante a participação na investigação. Ademais, a pesquisa qualitativa tem um viés instigador e transformador, exigindo dos sujeitos de pesquisa um ir e vir na busca dos dados e encaminhamento da solução.

Em particular, optamos pela metodologia da resolução de problemas. Para Duval (2011 apud Brandt;Moretti, 2018), a resolução de problemas corresponde a atividade central e emblemática da Matemática, representando um eixo organizador do ensino desta disciplina, e que permite desenvolver a capacidade de comunicação, cooperação e perseverança.

Pozo (1998) define problema como uma situação nova, diferente ou difícil, um obstáculo entre a proposição e a solução, onde 0 indivíduo ainda não dispõe de um caminho para a busca de soluções, o que exige investigação e tomada de decisões. 
A resolução de problemas é uma ferramenta básica, que [...] pressupõe promover nos alunos 0 domínio de procedimentos, assim como a utilização de conhecimentos disponíveis, para dar respostas a situações variáveis e diferentes (POZO, 1998, p. 9).

Para Schoenfeld (1985), a resolução de problemas viabiliza aos alunos mobilizar conhecimentos ou informações que estão ao alcance deles, o que oportuniza ampliar os próprios conhecimentos conceituais, exercitar uma bagagem cognitiva e motivacional e ainda favorecer a aquisição de procedimentos e atitudes adequadas. Estes fatores permitem ao aluno ampliar a visão que têm dos problemas matemáticos, do mundo em geral e desenvolvem a autonomia e autoconfiança.

Pozo (1998) argumenta que um problema deve ser concebido de modo a permitir ao aluno 0 desenvolvimento de estratégias mais sofisticadas, contrapondo a intuição e a utilização de estratégias mais básicas, como a da tentativa e erro.

Em relação à Álgebra, Ponte (2005), Tinoco et al. (2008) e Gomes (2011) apontam que na escolaridade básica ainda permanecem dificuldades dos alunos em reconhecer e lidar com a linguagem algébrica em problemas.

Um dos fatores de dificuldades com a situação descrita acima se relaciona com a premissa atual onde 0 "[...] ensino da Álgebra reside na ênfase habitualmente dada ao simbolismo algébrico, isto é, com foco na sintaxe, mas com pouca ou nenhuma associação com a semântica (BIANCHINI; MACHADO, 2010, p. 354).

Gómez-Granell (1997 apud Gomes, 2011) destaca duas tendências no ensino. A tendência sintática se baseia na manipulação simbólica por meio de regras, enquanto que a tendência semântica enfatiza aspectos conceituais da matemática, de modo que os alunos entendam ou construam o significado das operações e dos conceitos. Torna-se, assim, necessário "[...] integrar ambas as tendências, pois, como ocorre em qualquer linguagem, dominar a linguagem matemática requer conhecer seus aspectos sintáticos e semânticos" (GÓMEZ-GRANELL, 1997, p. 274 apud GOMES, 2011, p. 13).

As pesquisas de Medeiros (2001), Ponte (2005) e Tinoco et al. (2008) indicam que os estudantes ainda crêem que problemas verbais possam ser resolvidos pela aplicação das operações aritméticas usuais, bastando identificar qual a operação a ser utilizada, não sendo necessário planejamento, busca de significado ou uso de outras estratégias e, mais especificamente, a escrita algébrica.

Neste mote, muitos alunos que saem do Ensino Médio ainda não compreendem o papel da escrita algébrica como ferramenta organizadora da resolução de problemas. Na transição do Ensino Médio para o Superior e, em especial, nas licenciaturas, tornam-se necessárias pesquisas que indiquem as lacunas na formação algébrica dos alunos e que sirvam "[...] de base para a conscientização dos professores sobre a necessidade de mudança (TINOCO et al., 2008, p. 2-3).

Fiorentini, Miorim e Miguel (1993) ressaltam que a linguagem simbólica ou escrita algébrica é uma potente forma de registro, extremamente sintética e econômica para descrever e solucionar problemas matemáticos, além de simplificar os cálculos.

Estas inegáveis atribuições fazem da escrita algébrica uma porta de acesso e uma condição necessária para que os alunos se insiram e se desenvolvam no pensamento matemático. Nos moldes do presente estudo, o pensamento algébrico pode estar envolvido e ser expresso em várias formas, seja através da linguagem natural, aritmética, gráfica e algébrica, sendo que esta "[...] se potencializa na medida em que, gradativamente, 0 estudante desenvolve uma linguagem mais apropriada a ele" (FIORENTINI; MIORIM; MIGUEL, 1993, p. 89).

Duval (2003) relembra que na atividade matemática os objetos matemáticos não possuem existência real, o que exige diversas formas de registros para acessá-los. Duval (2003) realça que as 
dificuldades no ensino e na aprendizagem perpassam pela diversidade e articulação de diversos tipos de registros de representação semiótica.

Descrevemos, no quadro 01, a tipologia de registros de representação semiótica utilizados na Educação Algébrica, adaptado de Duval (2003).

Quadro 01 - Alguns tipos de Representação Discursiva.

\begin{tabular}{|c|l|l|}
\hline & \multicolumn{1}{|c|}{ Representação Discursiva } & \multicolumn{1}{c|}{ Representação Não-Discursiva } \\
\hline $\begin{array}{c}\text { Registros } \\
\text { Multifuncionais }\end{array}$ & $\begin{array}{l}\text { Uso da Língua natural, em associações verbais (concei- } \\
\text { tuais) ou na expressão das formas de raciocinar, como a } \\
\text { argumentação ou a dedução. }\end{array}$ & $\begin{array}{l}\text { Figuras geométricas planas ou em perspectiva, apreen- } \\
\text { são operatória e não somente perceptiva e construções } \\
\text { geométricas. }\end{array}$ \\
\hline $\begin{array}{c}\text { Registros } \\
\text { Monofuncionais }\end{array}$ & $\begin{array}{l}\text { Representam os sistemas de escrita que se limitam a um } \\
\text { único tipo de registro de representação semiótica, como } \\
\text { os cálculos numéricos e a escrita algébrica. }\end{array}$ & $\begin{array}{l}\text { Gráficos do tipo cartesianos, assim como mudanças de } \\
\text { sistemas de coordenadas, interpolação e extrapolação. }\end{array}$ \\
\hline
\end{tabular}

Fonte: [Adaptado de Duval (2003)].

Duval (2003) observa que a compreensão na matemática requer que 0 aluno mobilize pelo menos dois registros de representação semiótica, ao se deparar com objetos matemáticos. Ainda, 0 referido autor indica que existem duas possibilidades de operação cognitiva: 0 tratamento e a conversão.

Na Matemática é usual a operação de tratamento, que ocorre quando as mudanças de representação semiótica acontecem dentro de um mesmo sistema. Na Álgebra, há a operação de tratamento ao se resolver uma equação ou um sistema de equações, assim como nas etapas da demonstração de teoremas.

Duval (2003) aponta que a compreensão está associada essencialmente a operação de conversão. Na conversão, as mudanças de representação semiótica devem ocorrer com uma mudança do sistema, possuindo um registro de chegada com uma forma distinta ao registro de partida, sem mudança dos objetos.

Na Álgebra, uma conversão muito usual ocorre na etapa de passagem dos dados de um enunciado de um problema, em língua natural, para o registro algébrico ou na explicitação de cálculos para encontrar as soluções numéricas. Para Duval (2003), as conversões favorecem um quadro para haver maior compreensão de objetos na Matemática, além de permitir formas de registro mais potentes e econômicas, em termos de funcionamento da cognição.

Estas inegáveis atribuições fazem da escrita algébrica uma porta de acesso e condição necessária para que os alunos se insiram e se desenvolvam no pensamento matemático. Nesse sentido, torna-se primordial 0 uso de problemas em que 0 indivíduo possa mobilizar pelos menos dois tipos de registros de representações semióticas, de modo a possibilitar o desenvolvimento da capacidade cognitiva.

\section{PROCEDIMENTOS METODOLÓGICOS}

A pesquisa foi viabilizada e analisada à luz da metodologia da resolução de problemas e de aspectos da Teoria de Representação Semiótica de Duval (2003). Neste mote, foram direcionados dois problemas envolvendo o tema 'Equações Diofantinas Lineares' a alunos ingressantes da licenciatura em Ciências de uma universidade pública situada no estado de São Paulo. 
Observamos que as equações diofantinas lineares são caracterizadas pela expressão algébrica $a x+b y=c$, com soluções (' $x$ ' e ' $y$ ') e parâmetros ('a', 'b' e 'c') naturais, para a qual são buscadas soluções inteiras ou naturais. Uma equação deste tipo pode ter um número finito ou infinito de soluções, assim como não haver solução (Rocque; Pitombeira, 1991).

Usualmente, os alunos secundaristas não concebem que uma equação possa ter mais de uma solução. Isto recai no que Chevallard, Bosh e Gascón (2001) denominam de contrato didático, que representa os acordos ou normas, explícitos ou implícitos, que regulam as interações didáticas entre 0 professor e 0 aluno.

Os alunos da instituição onde ocorreu a pesquisa obtêm ingresso mediante os resultados obtidos no ENEM. Ainda, as prerrogativas para o ingresso nessa instituição se situam na lei n. 12.711, que obrigatoriamente vinculam a reserva para ingresso:

[...] nos cursos de graduação, por curso e turno, de no mínimo 50\% (cinquenta por cento) de suas vagas para estudantes que tenham cursado integralmente 0 ensino médio em escolas públicas.

Parágrafo único. No preenchimento das vagas de que trata o caput deste artigo, $50 \%$ (cinquenta por cento) deverão ser reservados aos estudantes oriundos de famílias com renda igual ou inferior a 1,5 salário-mínimo (um salário-mínimo e meio) per capita (BRASIL, 2012, p. 1).

Em vista do público-alvo e aliada a intenção da licenciatura em formar professores de Ciências, era natural se esperar certas dificuldades com relação aos assuntos básicos da área de Matemática que permeiam o referido curso.

Para participar da pesquisa se inscreveram dez alunos recém-ingressantes do curso de Licenciatura em Ciências. Por meio de uma conversa inicial com os alunos, a grande maioria dos alunos manifestou que não haviam trabalhado com problemas, especificamente nas aulas de Matemática.

Alguns alunos informaram que haviam tido contato com problemas em aulas de Biologia, em situações experimentais ou na área de Humanas, onde eram propostas situações abertas para provocar 0 debate e estabelecer possíveis encaminhamentos para 0 entorno dos problemas sociais em discussão.

Diante destes dados, decidimos expor aos alunos considerações iniciais sobre a Educação Matemática e a importância da resolução de problemas, de modo a criar uma atmosfera de entendimento de nossa proposta de pesquisa.

Situamos que os alunos trabalhariam em dupla, para haver a possibilidade de trocas de ideias e favorecer a busca de soluções. Neste momento, o professor teria mínima ou nenhuma participação com relação à transferência de conhecimentos ou explicações, em vista da intenção do mapeamento do repertório das estratégias que os alunos dispunham para resolver as atividades a serem propostas.

Posteriormente, após a resolução dos dois problemas, seria aberta uma sessão de comunicação em forma de debate, de modo que os alunos exporiam os resultados e os modos de desenvolvimento dos problemas.

Nesta etapa, o pesquisador poderia intervir, por meio de questionamentos, para aprofundar o debate e possibilitar 0 surgimento de novas estratégias. Por último, a sessão de debates poderia colocar a situação em uma perspectiva de um possível trabalho deles; como professores, num futuro próximo.

Os alunos formaram espontaneamente cinco duplas, denominadas $D_{1}, D_{2}, D_{3}, D_{4}$ e $D_{5}$. Cada dupla receberia um total de três folhas, sendo previsto um tempo de execuçã̃o em torno de 90 
minutos. Estas três folhas foram entregues sequencialmente, conforme 0 andamento da sessão e recolhidas ao final.

Buscamos maximizar as condições que permitiriam a autonomia para a mobilização do aluno em enfrentar o problema e em resolvê-lo, pelo menos em parte, através da lógica interna e dos conhecimentos anteriores.

Assim, buscamos deixar claro o entendimento mútuo dos papéis (a não-intervenção do professor-pesquisador e da ação independente do aluno) e o respeito a estas condições, para garantir as condições para se efetivar a resolução dos dois problemas. Pedimos aos alunos que deixassem todos os registros por escrito, frente às situações propostas. Ainda, houve a gravação em áudio das manifestações orais dos alunos.

\section{A ANÁLISE MATEMÁTICA E COGNITIVA DOS PROBLEMAS}

As duas atividades envolveram equações diofantinas lineares do tipo $a x+b y=c$ com coeficientes e soluções no âmbito dos números naturais. Ainda, na análise matemática identificamos as variáveis didáticas, que, o segundo Gálvez (1996), são aquelas que o pesquisador ou professor podem escolher para desenvolver um problema.-

Também, descrevemos as variáveis cognitivas de tratamento e conversão que poderiam ser mobilizadas pelos sujeitos de pesquisa, conforme Duval (2003), descritas nas estratégias previstas para cada problema. Para 0 autor, as variáveis cognitivas correspondem a maneira de ver, designar, definir e raciocinar que cada registro permite pôr em prática.

\section{A ATIVIDADE 1: 0 PROBLEMA DO SORVETE}

0 objetivo da $1^{\text {a }}$ atividade (ver Quadro 02) foi um primeiro contato com uma situação cotidiana, envolvendo duas soluções naturais, possibilitando sucesso na explicitação e possibilidade da utilização da estratégia da tentativa e erro. Isto envolve, por parte dos sujeitos de pesquisa, a conversão do enunciado do problema em registro de representação em língua natural para o registro de representação numérico e, talvez, para o registro de representação algébrico.

Quadro 02 - 0 enunciado do 'Problema do Sorvete'.

Uma criança recebeu $R \$ 20,00$ e decide satisfazer seu sonho: tomar sorvete de palitos da marca PREDILETA.
A marca comercializa dois tipos principais de sorvetes de palito: sorvete de frutas, a base de água, por $R \$ 3,00$ a
unidade e sorvete de palito a base de leite, a $R \$ 4,00$ cada.
De quantos modos a criança pode comprar sorvete de fruta ou leite, considerando-se que a criança está decidida
a gastar toda a quantia de $R \$ 20,00$ ?

Fonte: 0 autor.

As variáveis didáticas envolvidas foram:

- os preços dos sorvetes de frutas ( $R \$ 3,00)$ e sorvete de leite $(R \$ 4,00)$, assim como 0 valor a ser gasto na compra de sorvetes $(R \$ 20,00)$, no domínio dos números naturais e de fácil manuseio em cálculos;

- a relação entre os preços, que permite a existência de duas soluções. 
Para o desenvolvimento das soluções do 'Problema do Sorvete' previmos duas estratégias de solução, dispostas em ordem decrescente de probabilidade de ocorrência e elaboradas face às variáveis cognitivas (Duval, 2003). As estratégias previstas foram:

$\mathbf{E}_{1}$ : A utilização de cálculos explícitos, através da tentativa e erro, que demanda a conversão do registro de representação em língua natural para o registro de representação numérico, assim como 0 tratamento dentro do registro numérico no conjunto dos números naturais. 0 aluno, sabendo que há somente dois tipos de sorvete (frutas, a $R \$ 3,00$ e de leite, a $R \$ 4,00$ ), por cálculo e obtém duas soluções: (i) 4 sorvetes de frutas e 2 sorvetes de leite; (ii) 5 sorvetes de leite;

$\mathbf{E}_{2}$ : 0 equacionamento do problema para a busca das soluções, que requer a conversão do registro de representação numérico em registro de representação algébrico. 0 sujeito equaciona 0 problema explicitamente $3 x+4 y=20$ - e a utiliza para a busca das soluções naturais.

\section{A ATIVIDADE 2: O PROBLEMA DO LABORATÓRIO}

A atividade objetivou que os alunos vivenciassem um problema que contém um número de soluções de maior ordem em relação à atividade anterior, de modo a dificultar a determinação de todas as soluções naturais pelo método da tentativa e erro. Isto envolve, por parte dos sujeitos de pesquisa, a conversão do enunciado do problema em registro de representação em língua natural para o registro de representação numérico, de modo a incentivar a mudança para o registro de representação algébrico, mais propício a busca de soluções.

Esta atividade apresentou o problema apontado no Quadro 03.

Quadro 03 - 0 enunciado do 'Problema do laboratório'.

Um laboratório dispõe de 2 máquinas para examinar amostras de sangue. Uma delas examina 30 amostras de cada vez, enquanto que a outra examina 25. Quantas vezes essas máquinas podem ser acionadas, individualmente ou ao mesmo tempo, para examinar exatamente 2 mil amostras? [Fonte: Adaptado de Roque; Pitombeira (1991)].

\section{Fonte: 0 autor}

As variáveis didáticas foram:

- o número de amostras que cada máquina pode investigar ( 25 e 30) e o número de amostras a serem examinadas (2000), de fácil manuseio em cálculos escritos;

- relação entre os dados numéricos, que exige organização e persistência na busca das quatorze (14) soluções;

Para o desenvolvimento das soluções do 'Problema do laboratório' previmos duas estratégias de solução, dispostas em ordem decrescente de probabilidade de ocorrência e elaboradas face às variáveis cognitivas (Duval, 2003). As estratégias previstas foram:

$\mathbf{E}_{1}$ : A utilização de cálculos explícitos, através da tentativa e erro, que abrange a conversão do registro de representação em língua natural para o registro de representação numérico, assim como 0 tratamento dentro do registro numérico no conjunto dos números naturais. 0 aluno, sabendo que há somente dois tipos de máquinas (a que examina 30 e a outra que examina 25 amostras), por cálculo explícito obtém quatorze (14) soluções: 


\begin{tabular}{|c|c|c|c|c|c|c|c|c|c|c|c|c|c|c|}
\hline $\mathrm{x}$ & 0 & 5 & 10 & 15 & 20 & 25 & 30 & 35 & 40 & 45 & 50 & 55 & 60 & 65 \\
\hline $\mathrm{y}$ & 80 & 74 & 68 & 62 & 56 & 50 & 44 & 38 & 32 & 26 & 20 & 14 & 8 & 2 \\
\hline
\end{tabular}

$\mathbf{E}_{2}$ : 0 equacionamento do problema para a busca das soluções, que abrange a conversão do registro de representação numérico em registro de representação algébrico, em ambos os sentidos. 0 sujeito equaciona o problema explicitamente como sendo $30 x+25 y=2000$, ou a forma equivalente $6 x+5 y=400$, e a utiliza para a busca das soluções naturais.

\section{DESCRIÇÃO E ANÁLISE INICIAL DOS RESULTADOS}

A seguir, passamos a apresentar a descrição e a análise inicial das duas atividades delineadas acima.

\section{DESCRIÇÃO E ANÁLISE DA ATIVIDADE 1: 'O PROBLEMA DO SORVETE'}

Após entregar a folha contendo 0 enunciado do 'Problema do sorvete', observamos rápida mobilização e intensa comunicação entre os participantes. $A$ dupla $D_{2}$ me perguntou se poderia haver mais de uma resposta. Retomei o combinado colocado antes do início da experimentação, relembrando aos alunos que a interpretação dos enunciados fazia parte da resolução da atividade proposta. No quadro 04 apresentamos a síntese dos resultados obtidos pelas cinco duplas.

Quadro 04 - Resultados da Atividade 01 '0 problema do Sorvete’.

\begin{tabular}{|c|c|c|c|c|c|}
\hline \multirow[b]{2}{*}{ Soluções corretas } & $\mathrm{D}_{1}$ & $\mathrm{D}_{2}$ & $\mathrm{D}_{3}$ & $\mathrm{D}_{4}$ & $D_{5}$ \\
\hline & 4 s.f. e 2 s... ${ }^{1}$ & 4 s.f. e 2 s.l. & $\begin{array}{c}4 \text { s.f. e } 2 \text { s.l. } \\
5 \text { s.l. }\end{array}$ & 4 s.f. e 2 s.l. & $\begin{array}{c}4 \text { s.f. e } 2 \text { s.l. } \\
5 \text { s.l. }\end{array}$ \\
\hline \multirow{2}{*}{ Solução faltante } & 1 & 1 & 0 & 1 & 0 \\
\hline & 5 s.l. & 5 s.l. & - & 5 s.l. & - \\
\hline Equacionou? & $\begin{array}{c}\operatorname{Sim} \\
4 x+2 y=20\end{array}$ & $\begin{array}{c}\operatorname{Sim} \\
3 x+4 y=20\end{array}$ & $\underset{4 A+2 B=20}{\operatorname{Sim}}$ & $\begin{array}{c}\operatorname{Sim} \\
3 x+4 y=20\end{array}$ & Não \\
\hline Utilizou a equação? & Não & Não & Não & Não & - \\
\hline
\end{tabular}

Fonte: 0 autor.

Observamos os resultados expressos no Quadro 04 e pudemos verificar que as duplas não tiveram dificuldade em encontrar uma das possíveis respostas. Dado que antes de se iniciar a resolução da atividade houve uma pergunta explícita sobre se haveria a possibilidade de haver mais de uma solução, percebemos a relação das soluções com o conceito de contrato didático, descrito em Chevallard; Bosh; Gascón (2001).

Estes autores relatam que é usual aos alunos da escolaridade básica suporem que problemas matemáticos sempre contêm somente uma solução. Esta constatação situa um alerta que tais percepções se mantêm e necessitam estar incorporadas ao trabalho das disciplinas 'conteúdistas' e de formação principalmente nos cursos de Licenciatura em Ciências ou Matemática.

1 Simbologia empregada: s.f.= sorvete de frutas $(R \$ 3,00)$ e s.I. $=$ sorvete de leite $(R \$ 4,00)$. 
Todas as duplas utilizaram a estratégia $\mathrm{E}_{1}$ (tentativa e erro) para registro dos cálculos. Isto caracterizou o uso das operações cognitivas de conversão do registro de representação em língua natural para o registro de representação numérico, assim como no tratamento dos dados numéricos pelos cálculos aritméticos usuais.

Quatro duplas escreveram uma equação, mas não a utilizaram na resolução do problema. Isto configurou que os alunos realizaram a operação cognitiva da conversão para o registro de representação algébrico, porém não possuem repertório de estratégias pessoais para utilizar este registro de forma efetiva para 0 encaminhamento e busca de soluções, o que vai de encontro com as considerações de Medeiros (2001) e Tinoco et al. (2008).

0 mesmo ocorrreu com as duplas $\mathrm{D}_{2}$ e $\mathrm{D}_{4}$, que escreveram corretamente a equação, mas não a utilizou para encontrar as soluções. Conforme destaca o protocolo 01 referente à dupla $D_{1}$, observamos que a escrita algébrica foi elaborada como se fosse uma tradução do registro em língua natural para o registro de representação algébrico. Duval (2003) relembra que a simples tradução não representa ganho cognitivo ao aluno, pois não favorece a compreensão nas atividades matemáticas.

Isto denota uma lacuna na formação dos sujeitos de pesquisa quanto ao uso e importância das diversas linguagens da Matemática. Isto pode ser interpretado como conseqüência do pouco uso da forma de discurso no ensino da Matemática, ao contrário da ênfase em se destacar a escrita algébrica, colocada por Duval (2011 apud Brand; Moretti, 2018).

Protocolo 01 - Resposta da dupla D1 ao problema do sorvete.

(I) Au crianca pode pode comproou 2 sowetes do tipo y'i 4 sorvetes do tipo $x$

$$
4 x+2 y=20,00
$$

Fonte: 0 autor.

Na dupla $D_{3}$, a escrita algébrica $(4 A+2 B=20)$ uma interpretação similar (ver protocolo 02).

Protocolo 02 - Resposta da dupla D3 ao problema do sorvete.

$$
\begin{aligned}
& 2 \text { tipos de sonvete } \\
& \text { afue } \rightarrow A=3,00 \\
& \text { liste } \rightarrow B=4,00 \\
& \operatorname{tot} A=20,00 \\
& \text { Possibilidade - de consumir } A \text { e B utilizmos } \\
& \text { - total de } 20,00 \text { ef } 4 A+2 B=20 \\
& 4.3+2.4=20
\end{aligned}
$$

Fonte: 0 autor. 


\section{DESCRIÇÃO E ANÁLISE DA ATIVIDADE 2: 'O PROBLEMA DO LABORATÓRIO’}

Para a atividade 2 cada dupla recebeu a folha que continha 0 enunciado do problema e espaço para a busca e registro das soluções. No quadro 05 organizamos os resultados obtidos pelas duplas.

Quadro 05 - Resultados da Atividade 02 obtidas pelas cinco duplas.

\begin{tabular}{|l|c|c|c|c|c|c|c|c|c|c|c|c|c|c|}
\hline & $\begin{array}{c}\mathrm{x}=0 \\
\mathrm{y}=80\end{array}$ & $\begin{array}{c}\mathrm{x}=5 \\
\mathrm{y}=74\end{array}$ & $\begin{array}{c}\mathrm{x}=10 \\
\mathrm{y}=68\end{array}$ & $\begin{array}{c}\mathrm{x}=15 \\
\mathrm{y}=62\end{array}$ & $\begin{array}{c}\mathrm{x}=20 \\
\mathrm{y}=56\end{array}$ & $\begin{array}{c}\mathrm{x}=25 \\
\mathrm{y}=50\end{array}$ & $\begin{array}{c}\mathrm{x}=30 \\
\mathrm{y}=44\end{array}$ & $\begin{array}{c}\mathrm{x}=35 \\
\mathrm{y}=38\end{array}$ & $\begin{array}{c}\mathrm{x}=40 \\
\mathrm{y}=32\end{array}$ & $\begin{array}{c}\mathrm{x}=45 \\
\mathrm{y}=36\end{array}$ & $\begin{array}{c}\mathrm{x}=50 \\
\mathrm{y}=20\end{array}$ & $\begin{array}{c}\mathrm{x}=55 \\
\mathrm{y}=14\end{array}$ & $\begin{array}{c}\mathrm{x}=60 \\
\mathrm{y}=8\end{array}$ & $\begin{array}{c}\mathrm{x}=65 \\
\mathrm{y}=2\end{array}$ \\
\hline $\mathbf{D}_{1}$ & - & - & - & - & - & - & - & - & - & - & - & - & - & - \\
\hline $\mathbf{D}_{2}$ & $(0 ; 80)$ & - & - & - & - & - & - & - & - & - & $(50 ; 20)$ & $(55 ; 14)$ & $(60 ; 8)$ & $(65 ; 2)$ \\
\hline $\mathbf{D}_{3}$ & $(0 ; 80)$ & - & - & - & - & - & - & $(35 ; 38)$ & - & - & - & - & - & - \\
\hline $\mathbf{D}_{4}$ & $(0 ; 80)$ & - & - & - & - & - & - & - & - & - & - & - & - & - \\
\hline $\mathbf{D}_{5}$ & $(0 ; 80)$ & - & - & - & - & $(25 ; 50)$ & - & - & $(40 ; 32)$ & - & $(50 ; 20)$ & - & $(60 ; 8)$ & $(65 ; 2)$ \\
\hline
\end{tabular}

Fonte: 0 autor.

Conforme 0 Quadro 05 se observa que muitas respostas deixaram de ser apontadas. Isto pode ser interpretado no viés do contrato didático, pois é usual na escolaridade básica problemas matemáticos apresentarem uma ou pouquíssimas soluções. Além disso, os alunos não têm repertório de estratégias para delinear todas as soluções, conforme as ponderações de Medeiros (2001) e Tinoco et al. (2008).

A dupla $D_{1}$ não conseguiu nenhuma resposta. Uma possível explicação para isto envolve um erro de cálculo, pois 2000 dividido por 25 resulta 80 , mas a dupla $\mathrm{D}_{1}$ indivou como resultado 76 (Protocolo 03).

Protocolo 03 - Resposta das duplas $D_{1}$ e $D_{3}$, respectivamente, ao problema do laboratório.

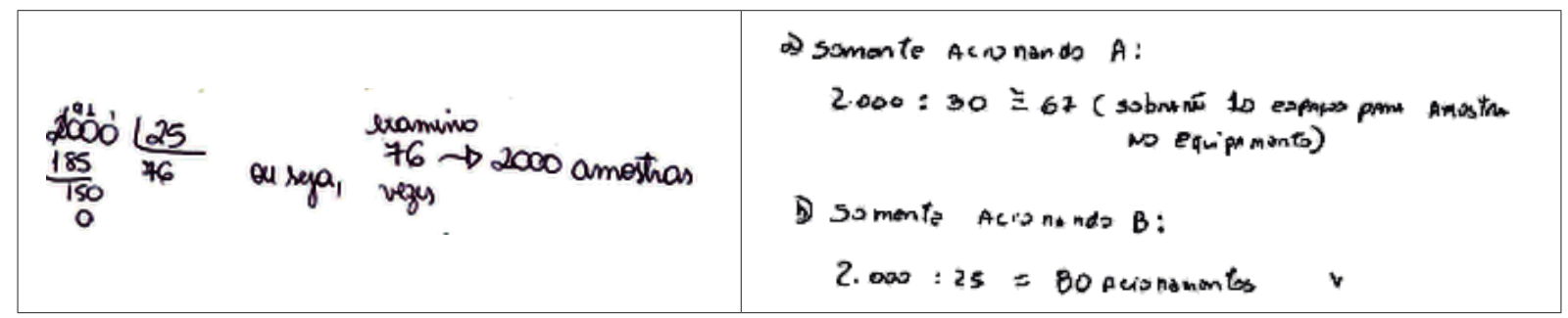

Fonte: 0 autor.

A dupla $\mathrm{D}_{2}$ obteve cinco soluções. Inicialmente, obtiveram o resultado (80;0), dividindo 2000 por 25. As outras possibilidades foram por tentativa e erro, sem nenhum tipo de organização em forma de tabela e também não escreveram a equação.

Para a dupla $\mathrm{D}_{3}$, as soluções foram o par $(80 ; 0)$ e o par $(35 ; 38)$. Também, apresentaram uma solução aproximada, ou seja, acionar 67 vezes a máquina $\mathrm{A}$. $\mathrm{A}$ dupla $\mathrm{D}_{4}$ também calculou a solução $(80 ; 0)$ e a solução aproximada (acionar 67 vezes a máquina $A)$. 
A dupla $D_{5}$ determinou seis soluções. Observamos que as alunas perguntaram se era necessário determinar todas as soluções. Retomamos o combinado e relembramos que as decisões e interpretação eram papel dos alunos.

Observamos que nenhuma dupla equacionou o segundo problema, preferindo utilizar a estratégia $\mathrm{E}_{1}$. Isto denota uma conversão do registro de representação em língua natural (o enunciado do problema) para o registro de representação numérico, assim como os tratamentos intrínsecos aos cálculos aritméticos.

Situando uma síntese envolvendo os dois problemas, os alunos realizaram o trabalho cognitivo de conversão do enunciado em língua natural para os registros numéricos. Porém, não tem no repertório de estratégias pessoais 0 entendimento que o registro de representação algébrico é a linguagem mais potente para se resolver os problemas matemáticos propostos.

\section{DISCUSSÃO DOS RESULTADOS}

Face às constatações delineadas acima passamos a promover uma abertura de debates e discussões sobre alguns dos resultados obtidos pelas cinco duplas de alunos. A intenção foi encaminhar uma reflexão para que os alunos percebessem a importância do registro de representação algébrico na solução de problemas matemáticos em função das variáveis cognitivas, que situam modos de ver, designar, definir ou raciocinar sobre as potencialidades que cada registro de representação permite pôr em prática, de acordo com Duval (2003).

0 encaminhamento da discussão tinha como fundamento questionar os alunos quanto às características em comum dos dados e soluções, que solicitavam o total de possibilidades de aquisição envolvendo duas espécies. Acreditamos ser esta etapa uma abertura para 0 entendimento do papel da escrita algébrica, a partir das estratégias desenvolvidas pelos próprios alunos para a busca das soluções.

Seguiu-se, então, o início de uma exposição, em que cada grupo apresentou os resultados obtidos para os demais. Os alunos escutaram, em silêncio, a apresentação das duplas.

Neste momento, diante da exposição dos resultados por cada dupla de alunos, nossa intenção era permitir uma reflexão inicial, por meio da comparação das soluções obtidas pelos demais. Após esta reflexão interna, os alunos poderiam comunicar, verbalmente, sobre os pontos em concordância e discordância, tecer comentários ou considerações em relação às soluções que eles não perceberam após a etapa de exposição.

Porém, observamos que os alunos se limitaram a apresentar os dados, não iniciando argumentação. Este tipo de postura pode ter decorrido de um contrato didático habitual em sala de aula, da escolaridade básica onde o professor é o detentor da palavra, cabendo aos alunos uma postura passiva, típico de escolas que trabalham somente com o ensino de técnica e algoritmos, sem propiciar momentos de resolução de problemas matemáticos, como é o caso dos alunos envolvidos nesta pesquisa. Assim, optamos por retomar os resultados, por meio de observações e indagações, para vislumbrar uma possibilidade de iniciar um debate.

Um primeiro fator que colocamos foi a nossa observação que os alunos utilizaram preferencialmente cálculos, por meio da tentativa e erro, para obter as soluções. Outro ponto que destacamos foi que quatro grupos até escreveram uma equação na forma algébrica, mas que não foi utilizada para 0 desenvolvimento do problema.

Em vista dessa reflexão inicial, passamos a questionar os grupos. 
Pesquisador: Por que vocês equacionaram?

Aluno 1: Na Matemática, você explica pela lógica.

Aluno 2: Você se organiza melhor para encontrar as soluções.

Aluno 1: No nosso caso não: nos equacionamos para fazer a demonstração lógica.

Estas respostas indicam haver por parte de alguns alunos uma noção intuitiva do papel do equacionamento como meio de encontrar soluções de problemas matemáticos. Porém, as manifestações escrita e verbal indicam um aspecto não operacional da escrita algébrica, ou seja, os alunos não dispõem de repertório que situe a escrita algébrica como ferramenta para resolver problemas, conforme discorremos no desenvolvimento teórico e metodológico desta pesquisa.

Em face disto, decidimos, então, relatar os resultados obtidos pelas duplas $D_{1}, D_{3}$ e $D_{4}$, porém, sem citar qual a fonte.

Pesquisador: Observando a produção de vocês, muitos fizeram o cálculo 2000 por 30 , que resulta 66 e tem resto 20.Também, fizeram a divisão de 2000 por 25 , que resulta 80 e tem resto zero. Por que fizeram isto?

Aluno 3: Para ter um valor teto para fazer os cálculos.

Pesquisador: E o que seria este 'valor teto'?

Aluno 3: É um valor que tomamos como uma base para se obter os outros.

Este modo de expressão implícita representa a quantidade máxima que se poderia obter, por meio de registro numérico e, assim, encontrar as outras soluções, por inspeção. Isto representou o que as citadas duplas realizaram. Porém, não buscaram todas as soluções. Para continuar a instigá-los na discussão, perguntamos:

Pesquisador: Como vocês poderiam organizar a produção de vocês na atividade 2? Aluno 1: Fazendo um gráfico.

Aluno 2: ... Ou uma tabela.

Neste momento, percebemos algumas respostas favoráveis, principalmente pela possibilidade da mudança por meio da conversão para o registro de representação gráfico, conforme expõe Duval (2003). Para este pesquisador este tipo de conversão pode proporcionar maior compreensão na atividade matemática.

Deste modo, questionamos como seria a organização em forma de tabelas.

Aluno 1: Melhor seria fazer uma tabela com três colunas.

Aluno 2: Na tabela entra a quantidade de amostras a serem examinadas por cada máquina e 0 total.

Em seguida, solicitamos aos alunos que expusessem alguns dos resultados obtidos. Como os alunos já haviam devolvido as folhas de resolução, estes foram refazendo mentalmente os cálculos obtidos anteriormente.

Aluno 5: Você pega 30x35= 1050 e vai calculando o que falta completar 02000.

Aluno 7: Ou fazer $65 \times 30=1950$ e, também, $2 \times 25=50$. 
Para melhor situar os resultados, a partir da colocação do aluno 7, esboçamos na lousa uma tabela de três entradas, indicando os valores mencionados, no quadro 06.

Quadro 06 - Organização das respostas do aluno 7, em forma de tabela.

\begin{tabular}{|c|c|c|}
\hline Número de peças inspecionadas por $\mathbf{A}$ & Número de peças inspecionadas por $\mathbf{B}$ & Total \\
\hline 65 & 2 & 2000 peças \\
\hline
\end{tabular}

Autor: 0 autor.

Ao perceber um princípio de organização na fala de um dos alunos, colocamos a questão: qual (is) seria(m) o(s) próximo(s) valor(es)?

Aluno 7: Você tira 5 daqui e 6 para lá...

Pesquisador: Como assim? Explique.

Aluno7: 0 próximo seria $60 \times 30=1800$ e 8x25 $=200$.

Aluno 7: E aí faz de novo: 5 para 6.

Em face das considerações desenvolvidas pelo aluno, que argumentou que estava operando pela lógica para se chegar aos resultados, perguntei 0 que ele queria dizer com a frase ' 5 para 6'.

Aluno 7: Você fraciona 25 e 30, os dados do enunciado. E daí, tira o mínimo.

Pesquisador: E o que é este 'mínimo'?

Aluno 7: São as partes que tem para cada um.

Pesquisador: E qual seria o próximo valor na tabela.

Aluno $7: 55 \times 30=1650$ e $14 \times 25=150$.

Pesquisador: E qual seria a lógica na montagem da tabela?

Aluno 7: Uma tabela vai diminuindo de 5 em 5 e a outra vai aumentando de 6 em 6.

Percebemos que 0 aluno conseguia operacionalizar os resultados, que remete a operação cognitiva de tratamento, conforme Duval (2003). Ainda, 0 aluno percebeu o padrão de regularidade, um ideia fundamental da Matemática, como ferramenta para descobrir as demais soluções.

A título de observação, a palavra 'mínimo', utilizada pelo aluno 7-, não tem correlação com 0 conceito matemático, mas revela aspectos associados à intuição e à lógica, que são inerentes ao raciocínio proporcional. Estas manifestações indicam a operacionalização de operações cognitivas importantes, porém sem um domínio conceitual das nomenclaturas do repertório matemático.

Aproveitamos a ocasião para explicar aos sujeitos de pesquisa a fala ' 5 para 6', que foi utilizada pelo aluno 7 . Em termos conceituais da Matemática, esta forma representa a fração $\frac{25}{30}=\frac{5}{6}$, que é utilizada para indicar a taxa de decrescimento dos valores do número de amostras que a máquina $\mathrm{A}$ processa e a taxa de crescimento do número de amostras que a máquina $\mathrm{B}$ faz, por intermédio do raciocínio proporcional.

A partir este ponto introduzimos uma questão, de modo a que os alunos explicitassem e percebessem a equação como uma forma de organizar dados para a resolução de um problema. 
Pesquisador: Qual seria a equação deste problema?

Aluno 7: $30 x+25 y=2000$.

Pesquisador: $E$ o que representam ' $x$ ' e ' $y$ '.

Aluno 4: 0 ' $x$ ' seria $A$ e ' $y$ ' seria $B$.

Pesquisador: A variável ' $x$ ' representa a quantidade de vezes que a máquina $A$ é acionada e a variável ' $y$ ' indica a quantidade de vezes que a máquina $B$ é acionada.

Aluno 1: A equação já indica o modo de cálculo.

Pesquisador: Como assim, me explique.

Aluno 1: 30 vezes 65 mais 25 vezes 2, que dá 2000.

Pesquisador: E qual seria o próximo:

Aluno 3: 30 vezes 60 mais 25 vezes 8, que dá 2000 .

Assim, os alunos começam a, explicitamente, descrever um importante papel do equacionamento: organizar as tentativas, em ordem crescente ou decrescente de valores de ' $x$ ', para realizar os cálculos. Porém, a função do equacionamento ainda continuava em níveis operatórios, centrado no registro de representação semiótica do tipo numérico, sem a compreensão do potencial inerente ao registro de representação algébrico.

Para continuar a percepção do significado dos elementos de uma equação, continuamos a questioná-los.

Pesquisador: Como olhar para a equação e explicar o '5' e o '6' que vocês mencionaram anteriormente.

Aluno: Divide a equação por 5 e, daí, fica $6 x+5 y=400$.

Para proporcionar um momento de síntese, a partir das próprias palavras dos alunos, fizemos alguns questionamentos:

- 0 que representam os dados nos enunciados dos problemas?

- Quais as dificuldades/facilidades encontradas?

Voluntariamente, as duplas de alunos responderam, com relação à $1^{\text {a }}$ questão. 0 quadro 07 sintetiza a resposta de algumas duplas.

Quadro 07 - Respostas a questão: 0 que representam os dados nos enunciados dos problemas?

\begin{tabular}{|c|l|}
\hline Dupla & \multicolumn{1}{c|}{ Comentários } \\
\hline$D_{1}$ & Os valores que fazem parte do sistema e que não mudam; uma relação que existe entre os valores. \\
\hline$D_{2}$ & São as constantes e, a partir delas, você vai desenvolver. \\
\hline$D_{3}$ & Os dados representam os coeficientes nos problemas que não variam. \\
\hline
\end{tabular}

Fonte: 0 autor.

As respostas dos alunos indicaram que houve uma percepção com relação ao papel que representam os dados nos problemas apresentados.

0 quadro 08 sintetiza algumas respostas quanto a $2^{\mathrm{a}}$ questão (dificuldades). 
Quadro 08 - Algumas respostas a questão: Quais as dificuldades encontradas?

\begin{tabular}{|c|l|}
\hline Dupla & \multicolumn{1}{|c|}{ Comentários } \\
\hline$D_{1}$ & $\begin{array}{l}\text { Trazer para a forma matemática; interpretação a linguagem do enunciado e trazer para a resolução } \\
\text { matemática dos problemas. }\end{array}$ \\
\hline$D_{2}$ & $\begin{array}{l}\text { No início das atividades, para perceber quando tinham diferentes valores e números, achar uma organiza- } \\
\text { ção certa; com o decorrer do outro exercício, com a melhora da organização, foi se tornando mais fácil. }\end{array}$ \\
\hline$D_{3}$ & A dificuldade é encontrar a expressão matemática correta. \\
\hline
\end{tabular}

Fonte: 0 autor.

As respostas tornam expressiva a dificuldade com a escrita e o uso da expressão algébrica na resolução de problemas matemáticos. Estas manifestações apontam que, apesar da intenção do currículo brasileiro em acentuar o trabalho com a Álgebra, os alunos ainda persistem em fazer uso de cálculos advindos da Aritmética para resolver problemas, em detrimento do uso e compreensão da escrita algébrica como ferramenta ideal e estratégia potencializadora da resolução de problemas.

Quanto à $2^{\mathrm{a}}$ questão, no quesito facilidade, o quadro 9 sintetiza algumas respostas:

Quadro 9 - Respostas a questão: Quais as facilidades encontradas?

\begin{tabular}{|c|l|}
\hline Dupla & \multicolumn{1}{|c|}{ Comentários } \\
\hline$D_{1}$ & Responder as questões de diferentes maneiras. \\
\hline$D_{2}$ & Explorar qualquer forma matemática para chegar aos resultados: equação, tabela, etc. \\
\hline
\end{tabular}

Fonte: 0 autor.

Foram interessantes as respostas destas duplas, pois revelam que os alunos começaram a compreender a importância do trabalho com diferentes registros de representação semiótica: aritmética, algébrica e tabela.

A partir das manifestações dos alunos podemos inferir que as atividades propostas ocuparam um lugar na aprendizagem, pois expressaram o que se situava no âmbito cognitivo deles. 0 emprego de vários registros de representação semiótica (língua natural, numérica e algébrica) permitiu situar um quadro para favorecer "[...] o desenvolvimento das capacidades cognitivas globais dos indivíduos, que é uma grande contribuição da Matemática para a educação do indivíduo (DUVAL, 2003, p. 15).

Ainda, as falas decorrentes da discussão permitiram certa compreensão dos elementos que compõe a equação descrita na forma algébrica e de seu papel para a busca de soluções em problemas.

\section{CONSIDERAÇÕES FINAIS}

A atividade foi concebida para possibilitar o uso de tópicos do currículo atual - operações aritméticas, par ordenado, representação algébrica de uma função linear - assim como explorar as seguintes operações do pensamento - cálculo mental, raciocínio proporcional, organização e observação dos resultados - dentro de uma abordagem ativa na resolução de problemas. 
Os encaminhamentos das soluções dos alunos durante a resolução dos dois problemas se situam em uma posição de conversão entre três registros de representação semiótica (natural, numérico e algébrico), o que favorece aspectos de compreensão, conforme aponta os estudos de Duval (2003).

Ficou marcante, nas respostas escritas e orais dos alunos, uma percepção inicial da importância da forma de equacionar problemas matemáticos e utilizá-la como ferramenta organizadora para a busca de soluções. A percepção desta importância pode desencadear, ao futuro professor de Matemática, uma forma de trabalho com a metodologia de resolução de problemas em sala de aula.

Vale destacar que estas manifestações verbais de resolução dos problemas puderam ser viabilizadas por meio da abertura de debates. Assim, na aula de Matemática, se introduz a oportunidade de manifestações dos alunos, seja pelos questionamentos efetivados pelo professor ou, talvez, em outras oportunidades, pela iniciativa dos próprios colegas.

0 modo ativo envolvido nos momentos de debate propiciou ambientação para que os próprios alunos repensassem e discutissem formas de pensar, o que recai na possibilidade de exploração do pilar 'aprender a aprender'.

Ao propormos as atividades que envolvesse a articulação entre a prática (a resolução de problemas) e a busca de referenciais teóricos e metodológicos (os registros de representação semiótica; 0 desenvolvimento de estratégias; a formação de professores), nossa intenção era oportunizar o exercício do futuro professor, conforme destacam Scheffer e Aimi (2004), desde o ingresso do licenciando na comunidade universitária.

A intenção de colocar as atividades em um momento extra-aula se inseriu na possibilidade de articular as discussões estabelecidas nas várias disciplinas usuais de um curso de Licenciatura, sejam as ligadas ao desenvolvimento de conhecimentos conceituais, como naquelas que realçam os conteúdos procedimentais a atitudinais, conforme Coll (1996).

Esta possibilidade em mediar e colocar as disciplinas do 'núcleo matemático' com as relativas ao 'núcleo didático ou pedagógico' em conjunção favorecem o que Lüdke (1994), Fiorentini et al. (2002) e Moreira e David (2005) denominam processo de reflexão, de conscientização e a formação de conhecimento sobre o processo de aprender a ensinar.

Vale ainda ressaltar que as falas dos alunos revelaram-se manifestações de dificuldades dos alunos em abandonar a tentativa e erro, que, provavelmente, ainda perdurará durante certo tempo. As manifestações ou dificuldades dos alunos revelaram que urge trabalhar com situações onde há a possibilidade da existência de uma ou mais soluções, no âmbito da natureza discreta das variáveis. Esta é uma forma de contrapor o contrato didático usual (Chevallard, Bosh, Gáscon, 2001), que recai usualmente na crença dos alunos que um problema tem somente uma solução.

Ainda, é importante que 0 reconhecimento de um objeto matemático através das várias representações possíveis deveria estar incorporado ao âmbito cognitivo dos alunos com maior prontidão, pois "[...] os únicos conhecimentos disponíveis e mobilizáveis por um indivíduo - e, portanto, operatórios para ele - são aqueles que permitem reconhecimentos relativamente rápidos" (DUVAL, 2003, p. 28)

Porém, notamos que isto não está presente no repertório dos alunos ingressantes das licenciaturas investigados na presente pesquisa. Assim, um convívio mais intenso com práticas, permitiria um espaço de socializar e democratizar os conhecimentos, sejam conceituais, procedimentais e atitudinais, de modo à melhor preparar profissionais para o trabalho docente (Coll, 1996). 
Em particular, torna-se imprescindível o fomento de atividades que estimulem nos alunos a percepção e uso da escrita algébrica como estratégia organizadora e otimizadora, de modo a diminuir ou até desestimular, talvez por completo, a estratégia da tentativa e erro para a resolução de problemas matemáticos.

\section{REFERÊNCIAS}

BARLOW, M. Le métier d'enseigner: essai de définition. Paris: Anthropos, 1999.

BIANCHINI, B. L.; MACHADO, S. D. A. A Dialética entre Pensamento e Simbolismo Algébricos. Educação Matemática Pesquisa, v. 12, n. 2, p. 354-368, 2010.

BRAND, C. F.; MORETTI, M. T. Aprendizagem da Álgebra segundo Raymond Duval. ReBECEM, Cascavel, (PR), v. 2, n. 1, p. 1-26, abr. 2018.

BRASIL. Base Nacional Comum Curricular. Brasília, DF: Ministério da Educação, 2017.

Lei n0 12.711, de 29 de Agosto de 2012. Brasília: Casa Civil da Presidência da República, 2012.

Parâmetros Curriculares Nacionais para o Ensino Médio. Brasília: SEMT/MECM, 1998.

Resolução CNE/CES 3, de 18 de fevereiro de 2003. Brasília: Diário Oficial da União, 2003. Seção 1, p. 13.

CHEVALLARD, Y.; BOSH, M.; GASCÓN, J. Estudar matemáticas: 0 elo perdido entre 0 ensino e a aprendizagem. Porto Alegre: Artmed Editora, 2001.

COLL, C. Psicologia e Currículo: Uma aproximação psicopedagógica à elaboração do currículo escolar. Tradução: Claúdia Schilling. São Paulo: Ática, 1996.

D’AMBROSIO, B. S. Formação de Professores de Matemática para o Século XXI: 0 grande desafio. Pro-Posições. Campinas, v. 4, n. 1/10, p. 35-41, mar. 1993.

DUVAL, R. Registros de Representações Semióticas e Funcionamento Cognitivo da Compreensão. In: MACHAD0, S. D. A. (org.). Aprendizagem em Matemática: Registros de Representação Semiótica. Campinas: Papirus, 2003, Cap. 1, p. 11-34.

FIORENTINI, D. A formação matemática e didático-pedagógica nas disciplinas da Licenciatura em Matemática. Revista de Educação, Pontifícia Universidade Católica, Campinas, n. 18, p. 107-115, jun. 2005.

FIORENTINI, D.; MIORIM, M. Â.; MIGUEL, A. Contribuição para um repensar ... a Educação Algébrica Elementar. Pro-Posições, v. 4, n. 1, mar. 1993, p. 78- 91. 
FIORENTINI, D.; SOUZA JR, A. J.; MELO, G. F. A. Saberes docentes: um desafio para acadêmicos e práticos. In: GERALDI, C. M. G.; FIORENTINI, D.; PEREIRA, E. M. A. (org.).Cartografias do trabalho docente: professor(a)-pesquisador(a). Campinas, SP: Mercado de Letras: Associação de Leitura do Brasil, 1998. p. 307-335.

FIORENTINI, D. et al. Formação de professores que ensinam matemática: um balanço de 25 anos da pesquisa brasileira. Educação em Revista, n. 36, p. 137-160, 2002.

GÁLVEZ, G. A Didática da Matemática. In: PARRA, C.; SAIZ, I. Didática da Matemática: Reflexões Psicopedagógicas. Tradução de: Juan Acuña Llorens. Porto Alegre: ArtMed, 1996. Cap. 2, p. 26-35.

GATTI, B. A. Formação de professores no brasil: características e problemas. Educ. Soc., Campinas, v. 31, n. 113, p. 1355-1379, out.-dez. 2010.

GOMES, M. L. M. Alguns aspectos históricos da álgebra e suas relações com o ensino na Educação Básica. Boletim GEPEM, n. 58, jan.-jun, 2011, p. 15-31.

LÜDKE, M. Formação de docentes para o ensino fundamental e médio: as licenciaturas. Rio de Janeiro: CRUB, 1994.

MEDEIROS, C. F. Modelos mentais e metáforas na resolução de problemas matemáticos verbais. Ciência \& Educação, v.7, n.2, p. 209-234, 2001. Disponível em: http://www.scielo.br/pdf/ciedu/v7n2/06.pdf. Acesso em 28 jan. 2017.

MOREIRA, P. C.; DAVID, M. M. M. S. 0 conhecimento matemático do professor: formação e prática docente na escola básica. Rev. Bras. Educ, n. 28, p. 50-61, abr. 2005. Disponível em: https://bit.ly/310I0jB. Acesso em: 21 mai. 2017.

PERRENOUD, P. A prática reflexiva no ofício de professor: profissionalização e razão pedagógica. Tradução de Cláudia Schilling. Porto Alegre: Artmed, 2002.

PERRENOUD, P. L'école face à la complexité. Genève : Service de la recherche sociologique \& Faculté de psychologie et des sciences de l'éducation, 1993.

PONTE, J. P. Números e álgebra no currículo escolar. 2005. Disponível em: https://bit.ly/2D2hsI4. Acesso em: 12 nov. 2016.

POZO, J. I. A solução de problemas: aprender a resolver, resolver para aprender. Porto Alegre: Artmed, 1998.

ROCQUE, G. L.; PITOMBEIRA J. B. Uma equação diofantina e suas resoluções. Revista do Professor de Matemática, São Paulo, v. 19, p. 39-47, 1991.

SÃO PAULO. Programa de Formação de Professores da USP. São Paulo: Comissão Permanente de Licenciaturas (USP), 2004.

SCHEFFER, N. F.; AIMI, S. A extensão presente na Formação Inicial do Professor de Matemática na Região do Alto Uruguai. Revista Perspectiva.n. 103, p. 51-58, 2004.

SCHOENFELD, A. H. Mathematical Problem Solving. Nova York: Academic Press, 1985. 
STRAUSS, A. Pesquisa qualitativa: técnicas e procedimentos para o desenvolvimento de teoria fundamentada. Porto Alegre: Artmed, 2008.

TARDIF, M. Saberes docentes e formação profissional. Petrópolis, RJ: Vozes, 2002.

TINOCO, L. A. A. Caminhos da álgebra na escola básica, 2008. Disponível em: https://bit.ly/30WLuyy. Acesso em: 12 nov. 2017.

RECEBIDO EM: 29 jan. 2020

CONCLUÍDO EM: 02 abr. 2020 